\title{
The Comparison of Achilles Tendon Viscoelastic Properties in Elite Runners and Soccer Players
}

\author{
Elit Koşucu ve Futbolcularda Aşil Tendonunun Viskoelastik \\ Özelliklerinin Karşılaştırılması
}

\author{
Serkan Usgu, Yavuz Yakut, Murat Ali Çınar \\ Department of Pysiotherapy and Rehabilitation, Faculty of Health Sciences, Hasan Kalyoncu University, Gaziantep, Turkey
}

\begin{abstract}
S. Usgu
0000-0002-4820-9490

Y. Yakut

0000-0001-9363-0869

M. A. Çınar

0000-0003-2122-3759

Geliş Tarihi/Date Received: 14.01.2020
\end{abstract}

Kabul Tarihi/Date Accepted: 03.02.2020

Yayın Tarihi/Published Online: 24.06.2020

Yazışma Adresi /

Corresponding Author:

Serkan Usgu

Hasan Kalyoncu Üniversitesi, Sağllk Bilimleri Fakültesi, Fizyoterapi ve Rehabilitasyon Bölümü

E-mail:

serkan.usgu@hku.edu.tr

(C2020 Türkiye Spor Hekimleri Derneği. Tüm hakları saklıdır.

\begin{abstract}
Objectives: Tendon stiffness may change depending on training and demands of sports discipline. It is important to assess tendon stiffness in order to understand tendon function during training adaptation or to optimize rehabilitation in pathological conditions. The aim of this study is to describe and to compare Achilles tendon (AT) mechanical (viscoelastic) properties of elite runners and soccer players, and demonstrate their relationship with plantar pressure.

Materials and methods: A total of 17 soccer players (age: $25.8 \pm 3.4$ years) and 17 runners (age: $21.5 \pm 4.0$ years) participated in the study. Viscoelastic properties of their Achilles tendons were evaluated with a "MyotonPro" device. The measurement was performed $4 \mathrm{~cm}$ above the calcaneal tubercle in the prone position, while the athlete's ankle hanged from the table in a neutral position. An "Ottobock Esco Scan" device and the "Presto-Scan" software were used for static foot pressure measurements of the athletes. The percentage of pressure figures were recorded. All evaluations were performed at the pre-season period (July-August 2018) at soccer clubs and federation facilities.

Results: AT stiffness was found higher in soccer players than in runners, while elasticity was found lower $(p<0.05)$. Also, it was seen that soccer players gave more pressure to the dominant foot, while runners gave pressure to non-dominant foot $(p<0.05)$. In both groups, dominant side forefoot and rearfoot pressures were found similar $(p>0.05)$. There was no relationship of viscoelastic properties of the tendon with forefoot and rearfoot pressure in the groups.

Conclusions: The storage and release of elastic energy in the Achilles tendon is important in sports and human movements. Long-term training in different sports can change the viscoelastic properties of the Achilles tendon. The plantar pressure may not affect these properties. Further studies are needed to evaluate tendon characteristics of athletes in different sports using myotonometric measurements.
\end{abstract}

Keywords: Sport, Achilles tendon, stiffness

öz

Amaç: Tendon sertliği antrenman programları ve spor dalının ihtiyacına bağlı olarak değişebilir. Antrenmana adaptasyon sürecinde tendon fonksiyonlarını anlamak veya patolojik durumlarda rehabilitasyonu optimize etmek için tendon sertliğinin değerlendirilmesi önemlidir. Bu çalışmanın amacı elit koşucu ve futbolcuların aşil tendon (AT) mekanik (viskoelastik) özelliklerinin tanımlanması, karşıllaştırılması ve plantar basınç ile olan ilişkisinin gösterilmesidir.

Gereç ve Yöntemler: Bu çalışmaya 17 profesyonel futbolcu (yaş; $25.8 \pm 3.4$ yıl) ve 17 koşucu (yaş; $21.5 \pm 4.0$ yıl) dahil edildi. Aşil tendonu viskoelastik özellikleri "MyotonPro" cihazı ile değerlendirildi. Ölçümler, sporcular ayak bilekleri nötr 
pozisyonda masadan sarkacak şekilde yüz üstü yatış pozisyonunda iken kalkaneal tüberkülün $4 \mathrm{~cm}$ yukarısından gerçekleştirildi. Sporcuların statik ayak basınç ölçümü için "Ottobock Esco Scan" cihazı ve "Presto-Scan" yazılımı kullanıldı. Basınç değerleri yüzdelik olarak kaydedildi. Tüm değerlendirmeler sezon öncesi (Temmuz-Ağustos 2018), futbol kulüpleri ve federasyon tesislerinde gerçekleştirildi.

Bulgular: Üst düzey futbolcuların AT sertliği koşuculara göre daha fazla, esnekliği ise daha azdı ( $p<0.05)$. Ayrıca, futbolcular dominant ayaklarına daha fazla ağırık verirken, koşucuların non-dominant ayağa daha fazla ağırlık verdikleri gözlendi $(p<0.05)$. Her iki grupta sağ dominant ayağın ön ve arka ayak ağırlık aktarımı benzerdi $(p>0.05)$. Gruplarda tendon viskoleastik özellikleri ile ayak basınçları arasında bir ilişki bulunmadı ( $p>0.05)$.

Sonuç: Aşil tendonunda elastik enerjinin depolanması ve serbest bırakılması hem insan hareketleri için hem de sporda oldukça önemlidir. Farklı spor branşlarında uzun süreli antrenmanlar sporcuların Aşil tendonu viskoelastik özelliklerini değiştirebilir. Ayak plantar basıncı bu özellikleri etkilemeyebilir. Myotonometrik ölçümleri kullanarak farklı branşlardaki sporcuların tendon özelliklerini değerlendiren çalışmalar gerekmektedir.

Anahtar sözcükler: Spor, aşil tendonu, sertlik

Available at: http://journalofsportsmedicine.org and http://dx.doi.org/10.5152/tjsm.2020.185

Cite this article as: Usgu S, Yakut Y, Cinar MA. The comparison of Achilles tendon viscoelastic properties in elite runners and soccer players. Turk J Sports Med. 2020;55(4):276-83.

\section{GÍRIS}

Aşil tendonu (AT) vücuttaki önemli ve işlevsel tendonlardan biridir. Gastroknemius ve soleus kaslarının ortak tendonu olan aşil tendonu üç farklı eklemi kat eder. Tendonlar kasların oluşturduğu kuvveti iletmek, elastik enerjiyi depolamak ve serbest birakmaktan sorumlu yapılardır (1). Bu özellik insan hareketlerinde kas-tendon kompleksinin (KTK) etkin bir șekilde çalışması ve özellikle sportif hareketlerdeki verim için oldukça önemlidir $(2,3)$. AT problemleri sıklıkla dayanıklılık sporlarında gözlenmektedir. Kariyerleri boyunca orta-uzun mesafe koșucularında \%52, futbolcularda \%28 oranında aşil tendon yaralanması bildirilmiştir (4).

Tendonların mekanik özelliklerinden biri sertliktir. Tendonun sertliği çeşitli yüklenme koşullarında ve tendinopatilerde değișiklik gösterebilmektedir. Özellikle AT patolojilerinde, tendondaki kuvvet iletimini etkileyen düşük sertlik değerleri bildirilmiștir $(5,6)$. Kas kuvveti olușu$\mathrm{mu}$ normal bulunsa da, değișen nöroplastisite motor performansı etkileyebilir (7).

Sporcunun fiziksel özellikleri ve antrenman programları, spor dalına bağlı olarak değișebilir. Yaralanmalar veya risk faktörleri spor dallarıyla ilişkilendirilebilir (8). Tendon sertliği uzun süreli antrenman yapan sporcularda yüksek bulunurken (9), kısa süreli egzersiz programlarına da adaptasyon göstermektedir (10).
Antrenmana adaptasyonda tendon fonksiyonlarını anlamak veya patolojik durumda rehabilitasyonu optimize etmek için tendon sertliğinin değerlendirilmesi önemlidir. Tendonun fonksiyonları pasif veya aktif hareketler sırasında değerlendirilebilir $(5,11)$. Ultrasonografi ile kombine edilen dinamometre yöntemi pasif tendon sertliğini değerlendirmede altın standart kabul edilse de, sadece laboratuvar ortamlarında kullanılabilecek pahalı ve kullanıcıya bağlı bir tekniktir $(12,13)$. Son yıllarda kas ve tendonların mekanik özellikleri (sertlik, tonus, elastisite) invazif olmayan, ağrısız myotonometrik ölçümler ile değerlendirilmektedir (14). Sporcu sağlığında, tendonun mekanik özellikleri ile yaralanmalar arasındaki ilișkilerin, mekanizmaların anlaşılmasına yönelik çok sayıda literatür bulunmaktadır.

Bilindiği kadarıyla AT problemlerinin sık gözlendiği spor dallarında özellikle üst düzey sporcuların katıldı ̆̆ı, myotonometrik ölçümlerle aşil tendonu mekanik özelliklerini karşılaştıran çalışmalar yoktur. Bu nedenle çalışmanın amacı, elit koşucu ve futbolcuların aşil tendonu mekanik (viskoelastik) özelliklerinin tanımlanması, karşılaștırılması ve plantar basınçla ilişkisinin gösterilmesidir.

\section{GEREÇ ve YÖNTEMLER}

Çalışmaya Türkiye Futbol Süper Ligi'nde mücadele eden profesyonel futbolcular ile milli 
koşuculardan oluşan toplam 46 üst düzey sporcu ( $\mathrm{n}=22$ futbolcu, $\mathrm{n}=24$ koşucu) dahil edildi. Sporcuların gerekli kriterleri sağlamaları açısından bir ön görüşme yapıldı. Bu kriterler; erkek, sağ dominant, son altı ay içerisinde AT yaralanması veya cerrahisi geçirmemiş olmak, rutin antrenmanları sürdürmek, profesyonel lisanlı olmaktı. Sol ayak dominant, son altı ayda kuadriseps veya triseps surae kaslarında "strain" öyküsü olan, diz veya ayak bileğinde geçirilmiş cerrahi öyküsü bulunanlar çalışmadan çıkartıldı. Kriterlere uygun olarak 34 sağlıklı sporcu ( $\mathrm{n}=17$ futbolcu, $\mathrm{n}=17$ koşucu) belirlendi. Sporcuların fiziksel özellikleri Tablo 1 'de verilmektedir. Hasan Kalyoncu Üniversitesi Girișimsel Olmayan Klinik Etik Kurulu tarafından 06.06.2018 tarih ve 2018-05 numaralı onay alındı. Ayrıca, Helsinki Deklarasyonu uyarınca yürütülen bu çalıșmada tüm katılımcıların katılım öncesi yazılı onayları alınd.

AT viskoelastik özellikleri MyotonPro cihazı (Myoton AS, Estonia) ile değerlendirildi. Ölçüm; probun uyarımından sonra serbest salınım tekniğine dayanmaktadır. Öncelikle prob cilde dik yerleştirilir ve deri altı dokunun sıkıştırılması için bir ön basınç uygulanır. Daha sonra dokunun salınımına neden olan kısa bir mekanik uyarım verilir ve dokuda üretilen salınım, bir ivme ölçerle kaydedilir. Bu ham sinyal daha sonra dokunun doğal salınımının karakteristik olmayan frekanslarını filtrelemek için işlenir ve filtrelenmiş hızlanma eğrisi dokunun viskoelastik özelliklerini hesaplamak için kullanılır (15). Sertlik; filtrelenmiş sinyalin eğrisinden matematiksel olarak şu formül ile çıkarılabilir; Sertlik $=\mathrm{a}_{0} \cdot \mathrm{m}_{\mathrm{prob}} / \Delta \mathrm{l}$. Burada, maksimum ivmelenme, $m_{\text {prob }}$ cihazın prob kütlesi ve $\Delta \mathrm{l}$ dokunun maksimum yer değiştirmesidir. MyotonPro testleri yüksek güvenilirliktedir $(14,16)$.

Tüm değerlendirmeler sezon öncesi (TemmuzAğustos 2018) futbol kulüpleri ve federasyon tesislerinde gerçekleştirildi. AT ölçümleri sporcuların ayak bilekleri nötr pozisyonda masadan sarkacak şekilde yüz üstü yattıkları pozisyonda alındı (Şekil 1). AT ölçümü, tendonun distal insersiyosu (kalkaneal tüberkül) belirlendikten sonra bu noktanin $4 \mathrm{~cm}$ yukarisindan gerçekleştirildi (13). Myotonometrik ölçüm üç kez tekrarlandı ve ortalamalar kaydedildi. Yalnızca \%3'ten düşük değişkenlik katsayılı ölçümler dikkate alındı. Aksi durumda ölçümler tekrar edildi. Dominant tarafın belirlenmesinde sporcunun topa vurduğu ayak sorgulandı.

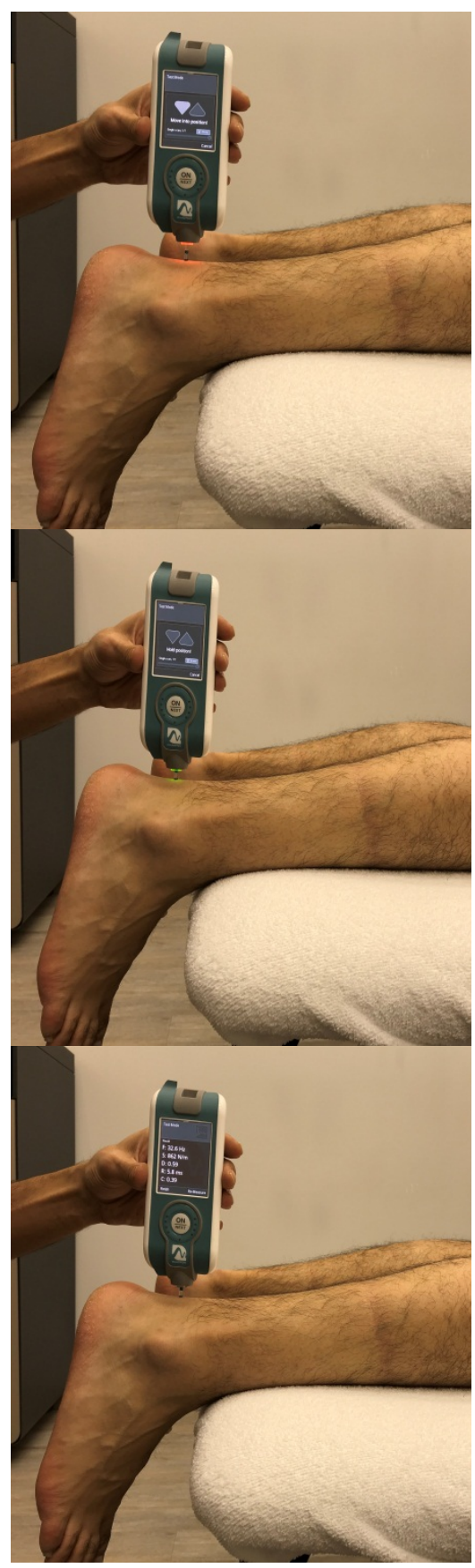

Şekil 1. Aşil tendonu myotonometrik ölçümü 
Sporcuların statik ayak basınç ölçümü için EsCoScan (EsCo Orthopädie Service GmbH, Germany) cihazı ve "Presto-Scan, Class I Rule 1, per MDD 93/42/EEC Annex IX, USA" yazılımı kullanıldı. Cihaz yaklaşık $5 \mathrm{~mm}$ kalınlığında olup $44 \times 37 \mathrm{~cm}$ sensör alanı bulunmaktadır. Rezistif sensör teknolojili cihazda toplam 2288 adet sensör yer almaktadır. Basınç ve kuvvet verileri 40 Hz'e kadar alınabilmektedir. Statik ölçümler, kişi ayakta gevşek pozisyonda, karşıda sabit bir noktaya bakarken yapıldı (Şekil 2). Statik değerlendirme ile her iki ayak için toplam temas alanına kıyasla sağa ve sola, ayak önü ve arkasına düşen yüzdelik değerler ölçüldü.

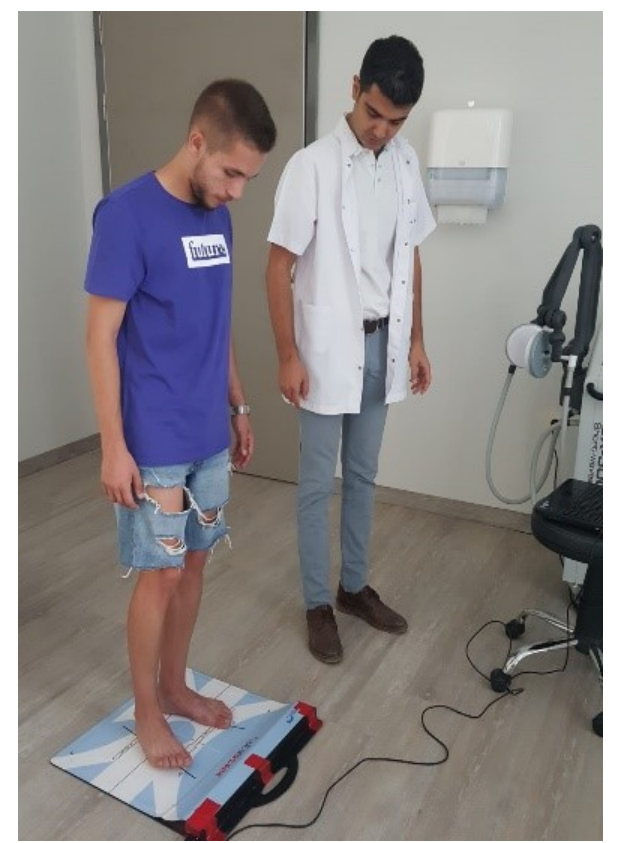

Şekil 2. Statik ayak değerlendirmesi

\section{Ístatistiksel analiz}

İstatistiksel analizler SPSS v23 yazılımı kullanılarak yapıldı. Verilerin normalliğini belirlemek için Kolmogorov-Smirnov testi kullanıldı. Verileri tanımlamak için ortalama ve standart sapma değerleri alındı. Grupların karşılaştırmaları için bağımsız örneklem $t$ testi kullanıldı. Ayak basınç dağılımı ve viskoelastik özellikler arasındaki ilişki için Pearson korelasyon analizi kullanıldı. Anlamlılık düzeyi p $<0.05$ olarak alındı.

\section{BULGULAR}

Sporcuların fiziksel özellikleri Tablo 1'de verilmektedir. Yaş, boy, vücut ağırlığı ve vücut kütle indeksi değerlerinde gruplar arasında istatiksel olarak anlamlı fark vardı $(\mathrm{p}<0.05)$.

Futbolcuların AT sertliği koşuculara göre daha fazla, esnekliği ise daha az olarak saptandı $(p<0.05)$. Ayrıca, futbolcular dominant ayağa daha fazla ağırlık verirken, koşucuların nondominant ayağa daha fazla ağırlık verdikleri gözlendi $(\mathrm{p}<0.05)$. Her iki grupta sağ dominant ayağın ön ve arka ağırlık aktarımları ise benzerdi ( $p>0.05$ ) (Tablo 2).

Tüm sporcuların ayak ön ve arka plantar basınç dağılımı ile Aşil tendonu mekanik özellikleri arasında anlamlı bir ilișki bulunmadı ( $p>0.05)$ (Tablo 3).

Spor dalları kıyaslandığında, dominant ayak ön ve arka bölüm plantar basınç dağılımları ile Aşil tendonu mekanik özellikleri arasında anlamlı ilişki bulunmadı ( $p>0.05)$ (Tablo 4).

Tablo 1. Sporcuların fiziksel özellikleri

\begin{tabular}{lrrrr}
\hline & Futbolcu & Koşucu & \multicolumn{1}{c}{ t } & \multicolumn{1}{c}{ p } \\
\hline Yaș $(\mathbf{y ı l})$ & $25.8 \pm 3.4$ & $21.5 \pm 4.0$ & 3.387 & $0.002^{*}$ \\
Boy $(\mathbf{c m})$ & $180.8 \pm 5.3$ & $175.8 \pm 4.7$ & 2.954 & $0.006^{*}$ \\
Vücut ağırlığı $(\mathbf{k g})$ & $76.4 \pm 5.1$ & $61.7 \pm 3.6$ & 9.690 & $<0.001^{*}$ \\
VKİ $\left(\mathbf{k g} / \mathbf{m}^{\mathbf{2}}\right)$ & $23.4 \pm 1.1$ & $20.0 \pm 0.6$ & 11.144 & $<0.001^{*}$ \\
\hline Değerler Ort \pm SS olarak; VKİ: vücut kütle indeksi; ${ }^{*}: p<0.05$ & &
\end{tabular}


Tablo 2. Sporcuların AT viskoelastik özellikleri ve plantar basınç dağılımları

\begin{tabular}{lrrrr}
\hline & Futbolcu & Koşucu & t & p \\
\hline Sertlik (Nm) & $926 \pm 71$ & $750 \pm 55$ & 8.108 & $<0.001^{*}$ \\
Elastisite (log) & $0.70 \pm 0.10$ & $0.84 \pm 0.14$ & -3.316 & $0.002^{*}$ \\
Sağ ayak (\%) & $50.4 \pm 3.3$ & $45.9 \pm 3.6$ & 3.823 & $0.001^{*}$ \\
Sol ayak (\%) & $49.6 \pm 3.3$ & $54.1 \pm 3.6$ & -3.823 & $0.001^{*}$ \\
Sağ ayak ön (\%) & $46.5 \pm 9.4$ & $48.4 \pm 10.2$ & -0.319 & 0.752 \\
Sağ ayak arka (\%) & $53.5 \pm 9.4$ & $51.7 \pm 10.2$ & 0.319 & 0.752 \\
\hline
\end{tabular}

Değerler Ort \pm SS olarak; Nm: Newton-metre; ${ }^{*}: p<0.05$

Tablo 3. Sporcuların AT viskoelastik özellikleri ve plantar basınç dağılımlarının ilişkileri

\begin{tabular}{lcc}
\hline Plantar basınç & \multicolumn{2}{c}{ Sporcu (n=34) } \\
\hline & Sertlik & Elastisite \\
\hline Sağ ayak ön (\%) & $0.031 ; 0.863$ & $-0.124 ; 0.486$ \\
\hline Sağ ayak arka (\%) & $-0.031 ; 0.863$ & $0.124 ; 0.486$ \\
\hline Değerler r; plarak & &
\end{tabular}

Tablo 4. Plantar basınç dağılımları ve AT mekanik özellikleri arasındaki ilişkiler

\begin{tabular}{llccc}
\hline Grup & Futbolcu & \multicolumn{2}{l}{ Koşucu } & \\
\hline Plantar basınç & Sertlik & Elastisite & Sertlik & Elastisite \\
Sağ ayak (\%) & $-0.110 ; 0.673$ & $0.228 ; 0.380$ & $0.115 ; 0.661$ & $0.011 ; 0.967$ \\
Sağ ayak ön (\%) & $0.056 ; 0.830$ & $-0.321 ; 0.209$ & $0.272 ; 0.290$ & $-0.045 ; 0.863$ \\
Să̆ ayak arka & $-0.056 ; 0.830$ & $0.321 ; 0.209$ & $-0.272 ; 0.290$ & $0.045 ; 0.863$ \\
\hline Değerler $r ;$ p olarak & & & &
\end{tabular}

\section{TARTIȘMA}

Çalışmanın amacı üst düzey futbolcu ve koşucularda AT viskoelastik özelliklerini tanımlamak, karşılaştırmak ve plantar basınç ile olan ilişskisini incelemekti. Sonuçta üst düzey futbolcuların AT sertlikleri daha fazla, dolayısıyla esneklikleri daha az bulundu. Sporcuların dominant ekstremite ayak ön ve arka basınçları ile AT mekanik özellikleri arasında anlamlı ilişki gözlenmedi. Yaptıkları spor dallarına göre kıyaslandığında yine anlamlı bir ilişki bulunmadi.

AT sertliğinin futbolcularda koşuculara göre fazla olması sporun ihtiyaçlarına adaptasyon ve sporcunun fiziksel özellikleriyle ilgili olabilir. Tendonun antrenmana adaptasyonu bilimsel olarak kanitlansa da $(9,10)$ hangi antrenman yönteminin (örneğin; kuvvet, pliometrik veya dayanıklılık) tendon sertliğini etkileyebileceği hakkında bilgi yetersizdir. Karateciler üzerinde yapılan çalışmada AT sertliği bu çalışmada elde edilenlerden düşük (17); netbolcularda ise yüksek bulunmuştur (18). Karateci ve netbolcular yaptıkları sporun ihtiyaçlarına göre farklı mekanik yanitlar ve tendon adaptasyonları gösterebilirler. Kısa veya uzun süreli antrenmana AT adaptasyonu ve sportif performans ile olan ilişkisi tartışmalıdır. En iyi performanslı uzun mesafe koşucularının kötü performansh olanlardan daha düşük AT sertliklerinin bulunduğu bildirilmiştir (19). Aksine en iyi koşu ekonomili veya performanslı orta ve uzun mesafe koşucularının AT sertliği ise daha yüksek bulunmuştur (20). 
Hareket sırasında kas-tendon etkileşimi karmaşıktır. Triseps surae kas tendon kompleksi (KTK) elastik enerji depolanması ve serbest bırakılmasındaki fonksiyonu nedeniyle önemlidir. KTK'nın yapısını anlamak için kasın fasikülü ve tendon uzunluğundaki değişiklikler farklı hareketlerde (örneğin; yürüyüş, koşma ve atlama) incelenmelidir. Yürüyüşün duruş fazında gastroknemius fasiküllerinde izometrik kontraksiyon meydana gelirken AT'de uzama gerçekleşir (21). Koşu veya sıçramanın duruş fazında gastroknemius fasiküllerinin kısalması (konsantrik kasılma) ve yine AT'nin uzaması gözlemlenmiștir (22).

KTK'daki bu mekanik değişimlerin iki avantajı vardır: AT'nin uzaması, elastik enerjinin verimli bir şekilde depolanmasına ve salınmasına izin verirken, kas fasiküllerinin uzamaması kuvvethız eğrisine göre kasın en etkili pozisyonda çalışmasını sağlamaktadır (2). Bu mekanik özelliklerin sportif performans ile ilișkisi net olmasa da, antrenmana adaptasyonun koşuculara göre farklı olması, fiziksel özelliklerle birlikte sporcularda KTK'nın antrenmana adaptasyonu olduğu anlamına gelebilir. Aynı branşın farklı mevkilerinde oynayan sporcuların fiziksel ve fizyolojik gereksinimleri farklılık gösterse de, AT sertliği benzer bulunmuştur $(23,24)$. Diğer mevkilere kıyasla orta saha futbolcularının daha fazla koştukları bilinmektedir. Uzun süreli antrenmanlar sonucu, mevkilere göre yüklenmeler mekanik açıdan fark etmesine rağmen AT'nin benzer adaptasyon göstermesi, performans için yeterli olabilmektedir.

Futbolcu ve koşucuların dominant ayak plantar basınçları farklı bulunsa da, Aşil tendonunun mekanik özellikleriyle ilişki saptanmadı. Spor branşları için ayak önü veya arkası arasındaki basınç dağılımı benzerdi ve AT mekanik özellikleriyle ilişki yoktu. Bu bulguların ayak plantar basıncının statik olarak değerlendirilmesiyle ilgili olduğunu düşündük. Ayak-ayak bileği birçok eklem ve kasın dinamik olarak etkileştiği bir bölgedir. Plantar fasya ve Aşil tendonunun dinamik viskoelastik özellikleri arasında pozitif korelasyon gösterilmiştir (25). Gastroknemiusun ayakta statik dururken izometrik kasılması, Aşil tendonunda ise minumum bir uzamanın meydana gelmesi nedeniyle plantar basınçtan bağımsız olarak ölçüm sırasında viskoelastik özelliklerin etkilenmediği kanısındayız.

Dominant ayak plantar basınç farkının ise spora özgü hareketlere bağlı farklı denge ve yüklenme stratejilerinden kaynaklanabileceği öngörüldü. Literatürde futbolcularda kaleye şut atma veya ani dönüş gibi futbola özgü hareketler sırasında karakteristik bir plantar basınç dağılımının olduğu ve uzun mesafe koşucularının plantar yüklenme düzeninin değiştiği gösterilmiştir $(26,27)$.

Her ne kadar plantar basıncın statik değerlendirmesi, spora özgü antrenmanda plantar basıncın dinamik ölçümü ile ilişkilendirilemese de, sporcuların vücut ağırlığı transferi veya denge adaptasyonları statik değerlendirmeler sırasında kaydedilen verilerden tanımlanabilir (28). Futbolcularda yapılan dinamik değerlendirmeler sırasında gözlenen basınç asimetrileri statik ölçümlerde elde edilenlerle benzerlik gösterse de (29), genel olarak dinamik hareketlerde ayak postürü ve kinematik özellikleri gastroknemius fonksiyonlarını etkilemektedir (30). Özellikle plantar fasya ve medial longitüdinal arkın çıkrık mekanizmasındaki rolü ayak önü ve arkası arasındaki yüklenimi değiştirmektedir (31). Plantar basınçtaki değișimlerin dinamik olarak değerlendirilmemesi bu çalışmanın sinırlılığı olarak görülse de; laboratuvar ortamını gerektirmesi, uzun zamanda yapılması ve ekonomik olmama faktörleri de dikkate alınmalıdır.

Sedanter bireylerde kas tonusu ile deri altı yağ kalınlığı arasında ters bir ilişkinin olduğunu ve tonusu azaltabileceği belirtilmektedir (32). Badmintoncularda Așil tendonu dışında kas viskoelastik özellikleri değerlendirilirken deri altı yağ kalınlığına dikkat edilmesi gerektiği bildirilmiştir (33). Antropometrik ölçümlerde sporcuların yağ ve kas oranları ayrı ayrı değerlendirilebilseydi, Așil tendonunun viskoelastik özelliklerine etkisi hakkında daha fazla bilgi edinebilirdik. 


\section{SONUC}

Așil tendonunda elastik enerjinin depolanıp serbest bırakılması hareket için önemlidir. Yıllar süren antrenmanlarla sporcuların AT viskoelastik özellikleri etkilenmektedir. Farklı branștaki üst düzey sporcuların dominant taraf ayak önü ve arkası plantar basınç dağılımları benzer olup, bu durum AT mekanik özelliklerini etkilememektedir. Myotonometrik ölçümler kullanılarak farklı branşlardaki sporcuların tendon sertliğini değerlendiren daha fazla çalışma yapılmalıdır. Ayrıca AT sertliğinin değerlendirilmesi, profesyonellere klinik anlamda önemli bilgiler sağlayabilir; sportif beceriler ile ilişkilendirme, yaralanmaların önlenmesi, kondisyon veya rehabilitasyon programlarında AT adaptasyonunun incelenmesi tendon ve yüklenmeye yanıtının anlaşılmasını destekleyebilir.

\section{Çıkar çatışması ve finansal destek}

$\mathrm{Bu}$ makalede çıkar çatışması ve finansal destek yoktur.

\section{REFERENCES}

1. Magnusson SP, Narici MV, Maganaris CN, Kjaer M. Human tendon behaviour and adaptation, in vivo. $J$ Physiol. 2008;586(1):71-81.

2. Fukunaga T, Kawakami Y, Kubo K, Kanehisa H. Muscle and tendon interaction during human movements. Exerc Sport Sci Rev. 2002;30(3):106-10.

3. Biewener AA, Roberts TJ. Muscle and tendon contributions to force, work, and elastic energy savings: a comparative perspective. Exerc Sport Sci Rev. 2000;28(3):99-107.

4. Kujala UM, Sarna S, Kaprio J. Cumulative incidence of achilles tendon rupture and tendinopathy in male former elite athletes. Clin J Sport Med. 2005;15(3):133-5.

5. Arya S, Kulig K. Tendinopathy alters mechanical and material properties of the Achilles tendon. J Appl Physiol (1985). 2009;108(3):670-5.

6. Finnamore E, Waugh C, Solomons L, Ryan M, West C, Scott A. Transverse tendon stiffness is reduced in people with Achilles tendinopathy: A cross-sectional study. PLoS One. 2019;14(2):1-12.

7. Rio E, Kidgell D, Moseley GL, Gaida J, Docking S, Purdam C, et al. Tendon neuroplastic training: changing the way we think about tendon rehabilitation: a narrative review. Br J Sports Med. 2016;50(4):209-15.

8. Janssen I, van der Worp H, Hensing S, Zwerver J. Investigating Achilles and patellar tendinopathy prevalence in elite athletics. Res Sports Med. 2018;26(1):1-12.

9. Wiesinger HP, Kösters A, Mueller E, Seynnes OR. Effects of increased loading on in vivo tendon properties: a systematic review. Med Sci Sports Exerc. 2015;47(9):1885-95.

10. Bohm S, Mersmann F, Arampatzis A. Human tendon adaptation in response to mechanical loading: a systematic review and meta-analysis of exercise intervention studies on healthy adults. Sports Med. 2015;1(1):1-18.

11. Cronin NJ, Lichtwark G. The use of ultrasound to study muscle-tendon function in human posture and locomotion. Gait Posture. 2013;37(3):305-12.

12. Bilston LE, Tan K. Measurement of passive skeletal muscle mechanical properties in vivo: recent progress, clinical applications, and remaining challenges. Ann Biomed Eng. 2015;43(2):261-73.

13. Liu CL, Li YP, Wang XQ, Zhang ZJ. Quantifying the stiffness of Achilles tendon: Intra- and inter-operator reliability and the effect of ankle joint motion. Med Sci Monit 2018;24:4876-81.

14. Leonard CT, Deshner WP, Romo JW, Suoja ES, Fehrer SJ, Mikhailenok EL. Myotonometer intra-and interrater reliabilities. Arch Phys Med Rehabil. 2003;84(6):928-32.

15. Gapeyeva H, Vain A. Methodical Guide: Principles of Applying Myoton in Physical Medicine and Rehabilitation. Tartu, Estonia: Müomeetria Ltd; 2008.

16. Kelly JP, Koppenhaver SL, Michener LA, Proulx L, Bisagni F, Cleland JA. Characterization of tissue stiffness of the infraspinatus, erector spinae, and gastrocnemius muscle using ultrasound shear wave elastography and superficial mechanical deformation. J Electromyogr Kinesiol. 2018;38:73-80.

17. Pożarowszczyk B, Pawlaczyk W, Smoter M, Zarzycki A, Mroczek D, Kumorek M, et al. Effects of karate fights on Achilles tendon stiffness measured by myotonometry. J Hum. 2017;56:93-7.

18. Pruyn EC, Watsford ML, Murphy AJ. Differences in lower-body stiffness between levels of netball competition. J Strength Cond Res. 2015;29(5):11971202.

19. Kubo K, Miyazaki D, Shimoju S, Tsunoda N. Relationship between elastic properties of tendon structures and performance in long distance runners. Eur J Appl Physiol. 2015;115(8):1725-33.

20. Fletcher JR, Esau SP, MacIntosh BR. Changes in tendon stiffness and running economy in highly trained distance runners. Eur J Appl Physiol. 2010;110(5):1037-46.

21. Ishikawa M, Komi PV, Grey MJ, Lepola V, Bruggemann GP. Muscle-tendon interaction and elastic energy usage in human walking. J Appl Physiol (1985). 2005;99(2):603-8.

22. Lichtwark G, Bougoulias K, Wilson AM. Muscle fascicle and series elastic element length changes along the 
length of the human gastrocnemius during walking and running. J Biomech. 2007;40(1): 157-64.

23. Cristi-Sánchez I, Danes-Daetz C, Neira A, Ferrada W, Yáñez Diaz R, Silvestre Aguirre R. Patellar and Achilles tendon stiffness in elite soccer players assessed using myotonometric measurements. Sports Health. 2019;11(2):157-62.

24. Kurihara T, Sasaki R, Isaka T. Mechanical properties of achilles tendon in relation to various sport activities of collegiate athletes. Proceedings, 30 th International Conference on Biomechanics in Sports. Melbourne, Australia. 2012.

25. Orner S, Kratzer W, Schmidberger J, Grüner B. Quantitative tissue parameters of Achilles tendon and plantar fascia in healthy subjects using a handheld myotonometer. J Bodyw Mov Ther. 2018; 22(1):10511.

26. Eils E, Streyl M, Linnenbecker S, Thorwesten L, Völker $\mathrm{K}$, Rosenbaum D. Characteristic plantar pressure distribution patterns during soccer-specific movements. Am J Sports Med. 2004;32(1): 140-5.

27. Karagounis P, Prionas G, Armenis E, Tsiganos G, Baltopoulos P. The impact of the Spartathlon ultramarathon race on athletes' plantar pressure patterns. Foot Ankle Spec. 2009;2(4):173-8.
28. Azevedo RR, da Rocha ES, Franco PS, Carpes FP. Plantar pressure asymmetry and risk of stress injuries in the foot of young soccer players. Phys Ther Sport. 2017;24:39-43.

29. Wong PL, Chamari K, Chaouachi A, Mao DW, Wisløff U, Hong Y. Difference in plantar pressure between the preferred and non-preferred feet in four soccerrelated movements. Br J Sports Med. 2007;41(2):8492.

30. Sakalauskaite R, Satkunskienè D. The foot arch and viscoelastic properties of plantar fascia and Achilles tendon. J Vibroeng. 2012;14(4):1751-9.

31. Pascual Huerta J. The effect of the gastrocnemius on the plantar fascia. Foot Ankle Clin. 2014; 19(4):701-18.

32. Agyapong-Badu S, Warner M, Samuel D, Stokes M. Measurement of ageing effects on muscle tone and mechanical properties of rectus femoris and biceps brachii in healthy males and females using a novel hand-held myometric device. Arch Gerontol Geriatr. 2016;62:59-67.

33. Bravo-Sánchez A, Abián $\mathrm{P}$, Jiménez $\mathrm{F}$, Abián-Vicén J. Myotendinous asymmetries derived from the prolonged practice of badminton in professional players. PLoS One. 2019;14(9):1-13. 